\title{
IMPLEMENTATION OF SCRUM FRAMEWORK ON WEB DEVELOPMENT OF MAPPING THE SALTED EGG PRODUCTION
}

\author{
Ginanjar Wiro Sasmito ${ }^{1}$, M. Nishom ${ }^{2}$ and La Ode Mohamad Zulfiqar ${ }^{3 *}$ \\ 1,2,3 Informatics Engineering, Politeknik Harapan Bersama, Tegal, Indonesia \\ 19anjar.dosen@gmail.com, ${ }^{2}$ nishom@poltektegal.ac.id, ${ }^{3}$ laodezr@gmail.com
}

\begin{abstract}
Indonesia as a producer of duck eggs is abundant enough to be the main raw material for making salted eggs. Publication of salted egg production has been presented using media websites, so that data can be accessed quickly and easily. However, the data displayed on the website has not used interesting visualization, the use of hyperlinks on the website is also not optimal. Even though one of the functions of the website is the utilization of optimal hyperlinks. Therefore, a website development is needed so that the data displayed on the website has good and interesting visualization and can maximize the use of hyperlinks. Development of a website for mapping salted egg production is done using the scrum framework. There are three core roles in the Scrum framework that work together to produce product enhancements triggered by each sprint. By using the Scrum Framework, the process of developing a website for mapping salted egg production can be resolved faster, because all scrum teams are involved in the process of completion.
\end{abstract}

Keywords - Scrum Framework, Web Development, Salted Egg Production, Mapping

\section{INTRODUCTION}

One of the most popular preserved egg products that created either by soaking the eggs into saturated salt or crusting it with salt and paste mixed for approximately a month or half month is the salted egg [1].The type of egg used in the production of the salted eggs is duck eggs because of their better characteristics compared to hens' [2].

Salted egg production is inseparable from the potential that exists in Brebes Regency, Indonesia as a producer of duck eggs that are abundant enough to be the main raw material for making salted eggs. Publication of salted egg production has been presented using media websites, so that data can be accessed quickly and easily [3]. However, the data displayed on the website has not used attractive visualization and the utilization of hyperlinks on the website is also not optimal. Though one of the functions of the website is the utilization of optimal hyperlinks [4]. Therefore, a website development is needed so that the data displayed on the website has good and interesting visualization and can maximize the use of hyperlinks, namely by creating a mapping website [5].

On this research the development of a website for mapping salted egg production is made to:

1. Data can be well integrated in each region

2. Optimizing hyperlinks on websites to be more interactive

3. Provide information with interesting visuals to the public and stakeholders

Received: July 31, 2019

Reviewed: January 17, 2020

Accepted: January 21, 2020

* Corresponding Author 
4. Provide graphical information about salted egg production in each region

5. Provide a report on salted egg production in each region

6. Provide information about salted egg production centers in an area along with duck farm area, number of ducks, number of producers of salted eggs, salted egg production per month and per year, regional maps, coordinate points, satellite photos and reports in graphic format.

In developing website-based salted egg production mapping products, the SCRUM framework is utilized, which works repeatedly and gradually in its development process [6]. The SCRUM framework is designed for agile software development models. A work group consist of only 3 to a maximum of 9 members who work together based on timeboxed iterations [7]. Different from the consideration of traditional and sequential modeling, the agile development model of effectiveness is more flexible and holistic, with the power to improve team excellence in achieving common goals. [8].

\section{RELATED RESEARCH}

Research conducted by permana 2015 [9], has implemented the Scrum method in management of software development projects. The research is motivated by the optimization of performance in companies where companies always do various approaches for business profits boost. The variations of business processes are able to affect its management since there are the diversity between one with another company. Based on the research that has been done, it is produced that:

1. Project quality and risk look faster.

2. In the final sprint, business changes and customer feedbacks are able to seen.

3. The project acceleration is real-time shown.

4. Live applications can be accomplished in the stockpile per product.

Basso et al, 2014 conducted a study of combining Model-driven engineering and Scrum to produce web information systems. In his research proposed a new pre-prototype based methodology, which combines practice to achieve rapid feedback from clients from model driven engineering and Scrum-based agile methods. The study also reports realworld case studies about developing web information systems. In his research, it was produced that the development of information systems that combined the Model Driven Engineering (MDE) and Scrum approach enabled the design and validation of the preprototype model system more quickly [10].

Schraff and Verma, 2010 wrote a paper about supporting mobile application development projects in a just-in-time learning context by using SCRUM framework. They explain about the evaluation for the use of SCRUM to support the development of mobile-based software. They point that the creativity is very important in developing mobile-based technology, so that the most suitable success in developing mobile applications is a agile model [11].

Salinas et al, 2012 in his paper entitle A Scrum based approach to CMMI maturity level 2 in web development environments describe that each of two between single or mixing of any agile practices has become one of the most attractive agile methodologies. Due to agile model would proceed profit, it is fascinating to the web community of utilizing agile approaches for developing web [12].

The popularity of SCRUM on the developing Global Software Development (GSD) recently is growing rapidly in agile method. However, current technique yet shows any attempts of methodically choose, check, and combine literature utilize on this topic [14].

On the paper written by Santos et al, 2015, it is showing that the combination of Challenge-Based Learning (CBL) Method and the SCRUM framework are able to deals 
with the market of the mobile application's market growth that force the developer to boost speed of the development process. It technique works by duplicating modern workplace using the combination methods of CBL and SCRUM. It also using agile methodology. Hence, the result of their research can make the better preparation process of development [15].

\section{RESEARCH METHOD}

This research was developed with software development methods, namely the agile method. Agile software development is an approach to establishing software with the collaborative efforts of self-regulating and cross-functional teams and the end users for working both the requirements and solutions [13]. The values and principles applied in Agile come from and support the Scrum framework [14].

Changes in customer thinking about their needs and desires, and predictions that are not in accordance with the requirements are the main principles of double recognition in the SCRUM method [7]. There are three core roles in the Scrum framework that work together to produce product enhancements triggered by each sprint. Together these three roles form the Scrum Team, including: Product Owner, Development Team and Scrum Master. The Scrum framework scheme that is applied in this study can be seen in figure 1 below [15]:

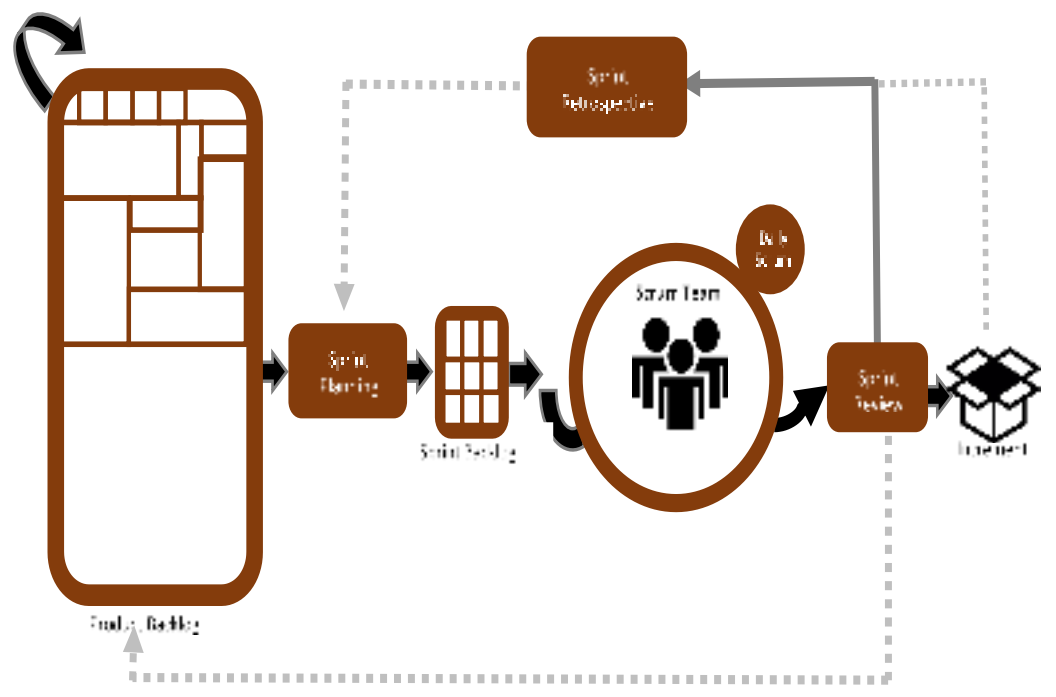

Fig. 1 Scrum Framework

\section{RESULT AND DISCUSSION}

\subsection{RESULT}

\section{a. Website Design}

The design of developing a website for mapping salted egg production is made using the Unified Modeling Language (UML). UML is a set of tools used to perform abstractions on a system or object-based software. UML is a language that is used to determine, visualize, build, and document when building a system with a particular programming language code [16]. Website development design can be seen in the following Figure 2: 


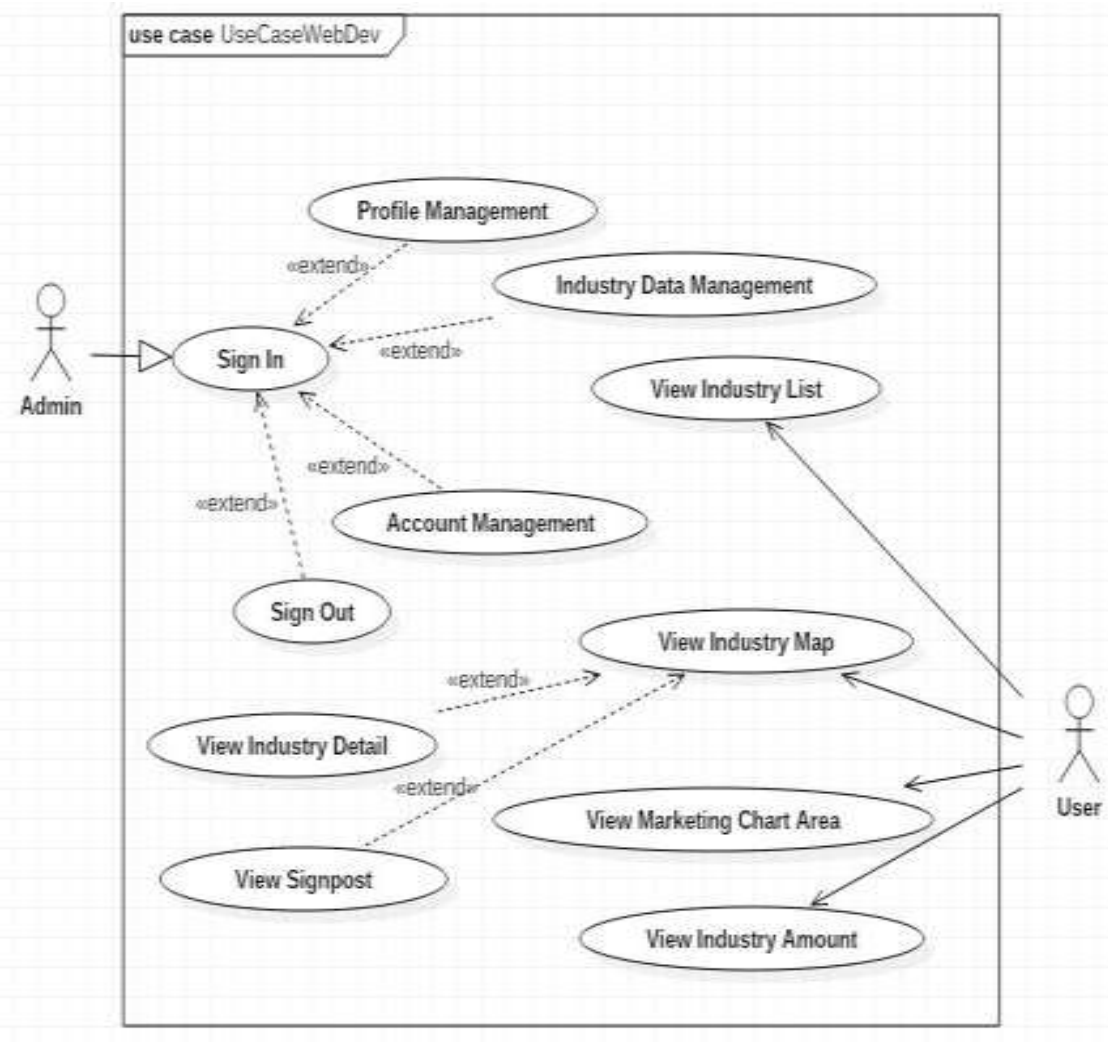

Fig. 2 Use case diagram

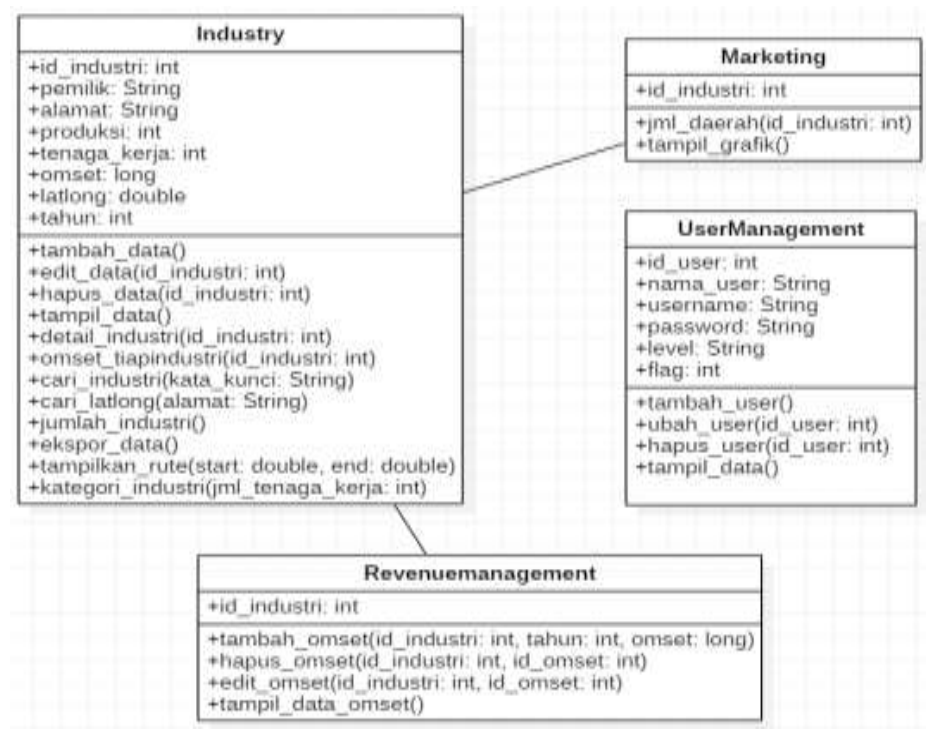

Fig. 3 Class diagram

\section{b. User Interface}

The interface produced in this study is divided into two, namely on the front end (for the user) and the back end (for the administrator). Both are made with a website platform using the PHP programming language which is a scripting for website development with MySQL databases: a relational database management system (RDBMS) that is open source [24]. The user interface that has been generated can be seen in the following Figures 4 and 5: 


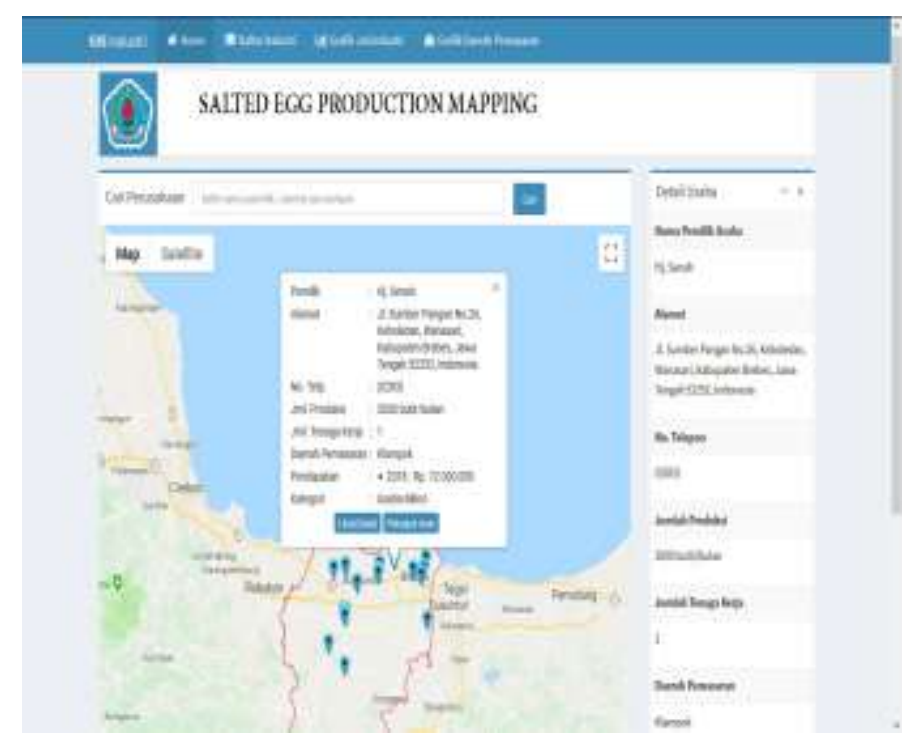

Fig. 4 Main menu

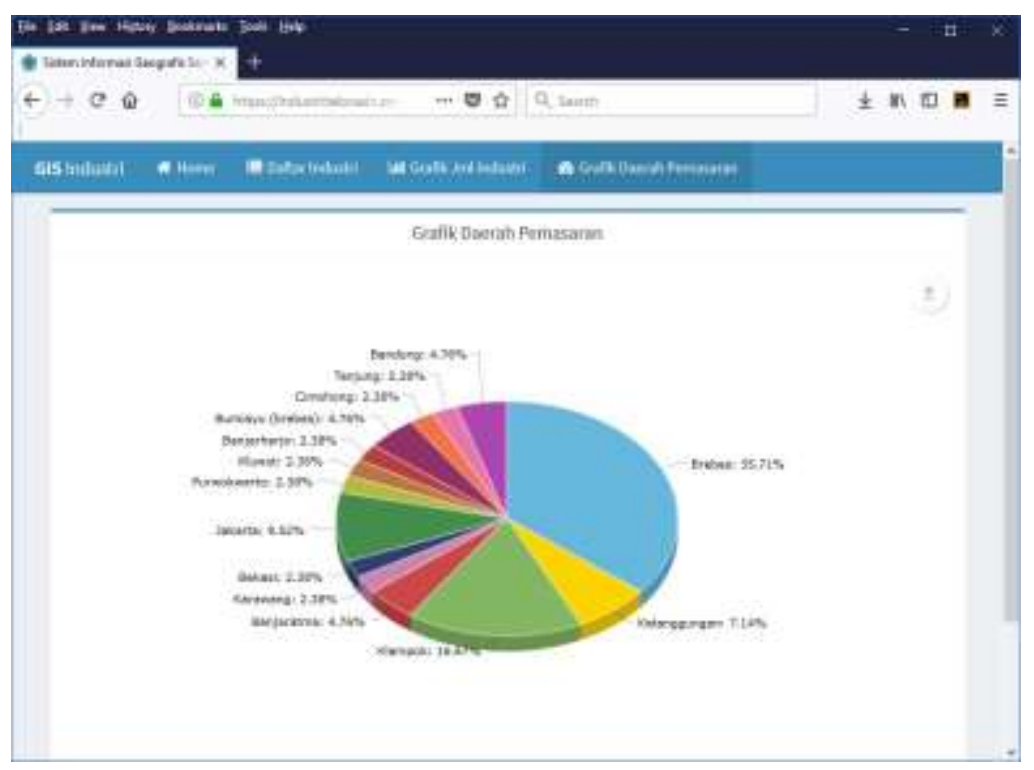

Fig. 5 Marketing area chart

\subsection{DISCUSSION}

Development of a website for mapping salted egg production is done using the Scrum framework, while the explanation is as follows:

\section{a. Product Backlog}

The product backlog aims to determine what priorities need to be worked out during the sprint, in this case a planning meeting is conducted involving the Product owner, Scrum Master and Development Team. In the planning meeting it was discussed about the media issues of information on salted egg production, processing of salted egg production data, reports on salted egg production, data integration and website hyperlinks. Besides discussing the problems also discussed the solution to the problem, namely by developing a mapping-based website. The instruments needed to solve the problem were also determined in this planning meeting. The management of product backlog is the responsibility of the product owner absolutely, so that the product owner indirectly determines the project vision / purpose. 


\section{b. Sprint Planning}

The Sprint Planning stage is the stage for formulating tasks that will be done in a website development project by the entire team, which are related to: system analysts, UI / UX design, coding / programming (front end and back end), and software testing. In this stage it is determined that the development team consists of 2 people without specific task specifications. This stage is done every time you will do a sprint.

\section{c. Sprint Backlog}

In the Sprint Backlog stage, the development team creates a real picture of the project that is being worked on, in accordance with the plans that have been agreed upon at the product backlog stage to the product owner. This stage is also done every time you will do a sprint.

\section{d. Daily SCRUM}

Daily Scrum stage is a stage where all team members share the results / progress of each of their work, both about system analysis, UI / UX design, coding / programming and software testing. The team also shared the problems experienced and provided solutions to the problems that existed. This stage is carried out every day during the sprint.

\section{e. Sprint Review}

Sprint Review is a stage where each team member demonstrates the results of his / her work in a sprint. This stage is carried out after one sprint is completed. In this case the team members jointly demonstrated a website development project mapping salted egg production.

\section{f. Sprint Retrospective}

This stage is done at the end of each sprint. In this case the development team presented the scrum process that was applied in developing a website for mapping salted egg production in the presence of the product owner and scrum master, then the product owner and scrum master gave suggestions relating to team performance during the implementation of Scrum.

\section{g. Increment}

This is the last step in the Scrum Framework. Increment is a work that can be inspected and completed to support empiricism at the end of the Sprint. In this case every time the sprint, then the end result is the increment which is a step to be able to achieve the goal / vision. This stage is also a stage of work on the project said to be completed by the product owner.

\section{CONCLUSION}

According to the results of the research that has been completed, it can be concluded that the process of developing a website for mapping salted egg production by applying the Scrum method can be resolved faster, because all scrum teams are involved in the completion process, so that data can be well integrated in each region and optimally, the information displayed is also interesting due to good visual data, information on the graph of salted egg production in each region can also be displayed, reports of salted egg production in each region can also be accessed and downloaded easily and the website can provide information about egg production centers salted in an area along with duck farm area, number of ducks, number of producers of salted eggs, salted egg production per month and per year, regional maps, coordinate points, satellite photos and reports in graphic format. 


\section{REFERENCES}

[1] C. Suey-Ping and T. Kuo-Hsuen, "Physicochemical Properties of Salted Pickled Yolks from Duck and Chicken Eggs," J. Food Sci., vol. 63, no. 1, 2008.

[2] L. Jian-Rong and H. Yun-Hwa, "Traditional Chinese food technology and cuisine," Asia Pacific Journa Clin. Nutr., vol. 13, no. 2, p. 147, 2004.

[3] K. T, S. Benjakul, and V. W, "Effects of salting processes and time on the chemical composition, textural properties, and microstructure of cooked duck egg," J. Food Sci., vol. 76, no. 2, p. 139, 2011.

[4] P. Le Page, "Responsive Web Design Basics | Web," Google Developers, 2017. .

[5] P. Fu, Web GIS: Principles and Applications. 2010.

[6] G. Verheyen, "Scrum: Framework, not methodology," 2013. [Online]. Available: https://guntherverheyen.com/2013/03/21/scrum-framework-not-methodology/. [Accessed: 24-Jul-2019].

[7] K. Schwaber, Agile Project Management with Scrum (Developer Best Practices) 1st Edition. Microsoft, 2004.

[8] H. Takeuchi, “The New New Product Development Game,” Ikujiro Nonaka, 1986. [Online]. Available: https://hbr.org/1986/01/the-new-new-product-development-game.

[9] Pemana and P. A. G., "Scrum Method Implementation in a Software Development Project Management," Int. J. Adv. Comput. Sci. Appl., vol. 6, no. 9, 2015.

[10] F. P. Basso, R. M. Pillat, F. R. Frantz, and R. Z. Frantz, "Combining MDE and Scrum on the rapid prototyping of web information systems,” Int. J. Web Eng. Technol., 2015.

[11] C. Scharff and R. Verma, "Scrum to support mobile application development projects in a just-in-time learning context," 2010.

[12] C. J. T. Salinas, M. J. Escalona, and M. Mejías, "A scrum-based approach to CMMI maturity level 2 in web development environments," 2013.

[13] K. Collier, "Introducing Agile Analytics: A Value- Driven Approach to Business Intelligence and Data Warehousing," in Agile Analytics: A Value-Driven Approach to Business Intelligence and Data Warehousing, 2011.

[14] C. Larman, Applying UML and Patterns: An Introduction to Object-Oriented Analysis and Design and Iterative Development. 2004.

[15] M. Fowler, "UML Distilled: A Brief Guide to the Standard Object Modeling Language," Pearson Paravia Bruno Mondad, 2004.

[16] D. Moris, Scrum : an ideal framework for agile project. In Easy Step. 2017. 
International Journal of Advanced Science and Technology Vol.134 (2020) 